\title{
Dental Students' Perception of Competencies related to Biomedical Sciences in the Dental Curriculum
}

\author{
${ }^{1}$ Yegane Guven, ${ }^{2}$ Sule Batu, ${ }^{3}$ Sevgi Turan, ${ }^{4}$ Emine Karsli
}

\section{ABSTRACT}

Aim: A dentist should be empowered to have knowledge of basic biological, medical, technical, and clinical sciences to distinguish the difference between normal and pathological conditions. The aim of this study was to describe the perception of dental students about competencies related to biomedical sciences in dental curriculum.

Materials and methods: A 26-question questionnaire was administered to fifth-year students who were the first group to complete the new integrated dental curriculum, to measure the extent to which the students had competences with biomedical science information, which were classified as "have knowledge," "have competence," and "have familiarity" according to the Profile and competences for the graduating European Dentist-update, 2009. A Likert-type 5-point scale was used $(1=$ not much, $5=$ a great deal) to evaluate the answers. The opinion of the students about qualification of education was also assessed with six questions.

Results: Fourteen questions related to "have knowledge" (Q1-17) of biomedical science subjects were rated somewhat, two rated them much, and one scored somewhat and much as equal on the Likert scale. Four questions related to "have competence" (Q18-24) were rated much, and three were rated somewhat. Students rated "have familiarity" with "pharmacology in general medicine" and "awareness of environmental issues relevant to dental biomaterials' use" $(Q 25,26)$ as somewhat. Most of the students approved of integrated education (60.7\%).

Conclusion: While planning and developing the curriculum aims to meet the practical needs of your future dentist, the importance of training based on competence should be taken into consideration.

Keywords: Biomedical sciences, Competency, Dentistry, Descriptive research, Students' evaluation.

How to cite this article: Guven Y, Batu S, Turan S, Karsli E. Dental Students' Perception of Competencies related to Biomedical Sciences in the Dental Curriculum. Int J Experiment Dent Sci 2018;7(1):18-22.

${ }^{1}$ Professor, ${ }^{2}$ Assistant, ${ }^{3}$ Associate Professor, ${ }^{4}$ Postgraduate Student

${ }^{1}$ Department of Basic Science, Faculty of Dentistry, Istanbul University, Istanbul, Turkey

${ }^{2,4}$ Department of Dentistry, Istanbul University, Istanbul, Turkey

${ }^{3}$ Department of Medicine, Hacettepe University, Ankara, Turkey

Corresponding Author: Yegane Guven, Professor, Department of Basic Science, Faculty of Dentistry, Istanbul University Istanbul, Turkey, Phone: +00902124142020, e-mail: guven@ istanbul.edu.tr
Source of support: Nil

Conflict of interest: None

\section{INTRODUCTION}

The principal aim of dental education is that the graduated dentist possesses extensive professional knowledge and skills and these competencies can be reflected in his/ her clinical practice. ${ }^{1,2}$ This can be achieved by integrated learning of subjects in the curriculum. This type of learning improves understanding of biologic principles, mechanisms, and basic concepts, and reinforces deep learning, which prepares students for lifelong learning. ${ }^{3,4}$

Integration of topics is important to prevent a crowded curriculum with redundant or marginally useful material, and to give students much more time to unite notions or develop critical thinking skills.

The Association for Dental Education in Europe (ADEE) DentEd III Profile and Competencies for European Dentists outlined major and supporting competencies, and was updated in 2009. ${ }^{5}$ Major competence of domain III (knowledge base, information, and information literacy) is related to "application of basic biological, medical, technical and clinical sciences." On graduation, a dentist must be competent to apply knowledge and understanding of the basic biologic, medical, technical, and clinical sciences to recognize the difference between normal and pathologic conditions/disorders relevant to clinical dental practice and understand their bases.

The graduated dentist should have acquired these competencies to perform his/her occupation in the best manner. The most important question is: Which competencies should be emphasized in which discipline in the dental curriculum? Achievement can be obtained through multidisciplinary integrated courses, which include basic and clinical sciences, and clinical medicine.

In assessing the quality of an academic program, student evaluations constitute an important parameter in the structuring of education. Effective evaluation provides valuable information that contributes to both student and course success. ${ }^{6}$

Therefore, in this study, we evaluated the outcomes of students' perception regarding the competencies related to biomedical sciences in the dental curriculum. 


\section{MATERIALS AND METHODS}

The present study was approved by the Ethics Committee of Istanbul University, Faculty of Dentistry (Approval number: 128/2016). We undertook this survey to measure the extent to which the students had competences with biomedical science information, which were classified as "have knowledge," "have competence," and "have familiarity" in line with the expectations set out in the profile and competences for the graduating European Dentistupdate, 2009. A questionnaire of 26 questions using a Likert-type 5-point scale was administered to fifth-year students $(n=56)$ from Istanbul University Faculty of Dentistry who were the first group to complete the new integrated dental curriculum. Medians and ranges of the Likert scale values for the 26 items were calculated. For this purpose, a Turkish language version of the DentEd III-ADEE document related to competencies was used. Cronbach's alpha was applied to quantify the reliability and internal consistency of the scale on the questionnaire.

The participation level of students to propositions related to education was also assessed with a six-question questionnaire. There were two different propositions opposite to each other. Positive and negative statements from the questions were selected in equal numbers.

The first three of these were regarding support "integrated education," and the remainder were about "conference-based education." A principal component analysis (PCA) with varimax rotation was performed to examine construct validity. Adequacy of the data for factor analysis was investigated using the Kaiser-Meyer-Olkin (KMO) measure of sampling adequacy and Bartlett's test of sphericity for the evaluation of questionnaire of qualification of education. The KMO value was 0.63 and the Bartlett's test for sphericity was significant $(\mathrm{p}<0.001)$, which suggested that this survey was suitable for PCA.

Statistical analysis was performed using IBM Statistical Package for the Social Sciences Statistics version 19 for Windows (SPSS Inc., Chicago, Illinois, USA).

\section{RESULTS}

Descriptive statistics and frequency distribution can be seen in Tables 1 and 2.

The internal consistency of the questionnaire was found to have a high reliability coefficient (Cronbach alpha: 0.92 for questions about knowledge, 0.84 for competence, 0.58 for familiarity, 0.80 for proposition integrated education, and 0.63 for conference-based education).

The mean scores of the 26 items on the 56 students' questionnaires showed the following results:

Of the 17 questions (Q1-Q17) related to "have knowledge" about biomedical science subjects in the curriculum regarding the scientific principles of sterilization, disinfection and antisepsis; cross-infection control; and disease processes, such as infection, inflammation, disorders of the immune system, degeneration, neoplasia, metabolic disturbances, and genetic disorders, 14 questions were rated somewhat on the Likert scale and two were rated much. The remaining question about oral manifestations of systemic disease was rated $\sigma o \mu \varepsilon \omega \eta \alpha \tau$ and much equally on the Likert scale.

Of the 7 questions (Q18-24) related to "have competence," questions 18, 19, 20, and 23 were rated much, and 21,22 , and 24 were rated somewhat. Students rated "have familiarity" with "pharmacology in general medicine" and "awareness of environmental issues relevant to dental biomaterials' use" $(\mathrm{Q} 25,26)$ as somewhat.

Using PCA with a criterion of eigenvalue $>1$, two factors were extracted that accounted for $65.84 \%$ of the total variance. The first factor accounted $37.7 \%$ of the total variance (items 1, 2, and 3, eigenvalue: 2.26) and was related to "integrated education." The second factor made up $28.14 \%$ of the total variance (items 4,5 , and 6 , eigenvalue: 1.69) and explained "conference-based education." In the evaluation of qualification of education in terms of frequency distribution, most students approved of integrated education (60.7\%). The number of students who neither agreed nor disagreed that "dental education must be based on the master-apprentice relationship" was quite high (33.9\%) (Table 3$)$.

\section{DISCUSSION}

Most of the answers related to "have knowledge" were rated somewhat, which may be accounted for by crowded classrooms and lecture-based courses. In this teaching method, information cannot be kept in the memory; on the contrary, it is superficial and is soon forgotten. Conway et $\mathrm{al}^{8}$ reported that when students were actively involved in learning and completing practical experiments, they tend to have a stronger memory. In our study, although the integrated modular curriculum is in force and comprehensive, these answers of the students indicate a lack of knowledge retention. Unused information disappears after a while. Biomedical science education must be emphasized in the clinical years of the dental school curriculum where the main aim is to achieve certain skills. This can be obtained in part through casebased and problem-based discussion. ${ }^{9}$

In our study, students had settled the memory of subjects of sterilization-disinfection and disease processes because these are highlighted many times in various clinical courses. ${ }^{10}$

Henzi et $\mathrm{al}^{3}$ performed a SWOT analysis (strengths, weaknesses, opportunities, and threats) of the dental curriculum, and "education based on memorization" was found as a weakness. 
Table 1: Descriptive statistics for the 26 questionnaire items $(n=56)$

\begin{tabular}{|c|c|c|c|c|}
\hline & Minimum & Maximum & Mean & $\begin{array}{l}\text { Standard } \\
\text { deviation }\end{array}$ \\
\hline \multicolumn{5}{|l|}{ Have knowledge of } \\
\hline Q1. The structure and metabolism of human body & 2.00 & 5.00 & 3.4107 & 0.80401 \\
\hline $\begin{array}{l}\text { Q2. The scientific principles of sterilization, disinfection and antisepsis, and cross- } \\
\text { infection control }\end{array}$ & 2.00 & 5.00 & 3.7857 & 0.77961 \\
\hline Q3. Leading the team on radiation protection measures & 1.00 & 5.00 & 3.2143 & 0.96699 \\
\hline Q4. The hazards of ionizing radiations and their effects on biological tissues & 1.00 & 5.00 & 3.3393 & 0.92002 \\
\hline $\begin{array}{l}\text { Q5. The scientific basis of dentistry, including the relevant biomedical sciences, } \\
\text { the mechanisms of knowledge acquisition, scientific method, and evaluation } \\
\text { of evidence }\end{array}$ & 2.00 & 5.00 & 3.2321 & 0.93402 \\
\hline Q6. Basis of biomedical sciences & 1.00 & 5.00 & 2.8929 & 0.90812 \\
\hline $\begin{array}{l}\text { Q7. The biological processes in the body to a sufficient depth to be able to exploit new } \\
\text { emerging biological technologies in clinical practice, especially in regenerative } \\
\text { medicine }\end{array}$ & 1.00 & 5.00 & 2.7857 & 0.70619 \\
\hline $\begin{array}{l}\text { Q8. The cellular and molecular basis of life including both eukaryotic and prokaryotic } \\
\text { cells }\end{array}$ & 1.00 & 5.00 & 3.3036 & 1.00760 \\
\hline $\begin{array}{l}\text { Q9. The biomedical sciences in the normal healthy individual at a depth relevant to } \\
\text { dentistry }\end{array}$ & 1.00 & 5.00 & 3.1429 & 0.77292 \\
\hline Q10. Disease processes, such as infection and inflammation & 2.00 & 5.00 & 3.6964 & 0.65836 \\
\hline Q11. Disorders of immune system & 2.00 & 5.00 & 3.2679 & 0.72591 \\
\hline Q12. Degenerative disturbances and neoplasia & 1.00 & 5.00 & 2.9464 & 0.79589 \\
\hline Q13. Metabolic disturbances and genetic disorders & 1.00 & 5.00 & 2.8929 & 0.86715 \\
\hline $\begin{array}{l}\text { Q14. Pathological features and dental relevance of common disorders of the major } \\
\text { organ systems }\end{array}$ & 2.00 & 5.00 & 3.3393 & 0.79262 \\
\hline Q15. Oral manifestations of systemic disease & 2.00 & 5.00 & 3.4107 & 0.65441 \\
\hline $\begin{array}{l}\text { Q16. The etiology and pathological processes of oral diseases to facilitate their } \\
\text { prevention, diagnosis, and management }\end{array}$ & 2.00 & 5.00 & 3.2679 & 0.72591 \\
\hline $\begin{array}{l}\text { Q17. The science of dental biomaterials and their limitations } \\
\text { Be competent at }\end{array}$ & 1.00 & 5.00 & 3.0000 & 0.71351 \\
\hline Q18. I can use the basic science information to learn functioning of the human body & 2.00 & 5.00 & 3.3036 & 0.87219 \\
\hline Q19. I can use the basic science information for clinical skills & 2.00 & 5.00 & 3.4464 & 0.78438 \\
\hline $\begin{array}{l}\text { Q20. I can implement sterilization, disinfection and antisepsis, and cross-infection } \\
\text { control in the practice }\end{array}$ & 2.00 & 5.00 & 3.9286 & 0.80582 \\
\hline Q21. I can implement the ionizing radiation regulations on radiation protection measures & 1.00 & 5.00 & 3.2500 & 0.93905 \\
\hline Q22. I can lead the dental team on radiation protection measures & 1.00 & 5.00 & 3.0179 & 1.10357 \\
\hline $\begin{array}{l}\text { Q23. The ability to apply this knowledge and understanding of basic biological, } \\
\text { medical, and clinical sciences to everyday real life and clinical situations }\end{array}$ & 1.00 & 5.00 & 3.3214 & 0.91666 \\
\hline $\begin{array}{l}\text { Q24. I can apply the information of pharmacology and therapeutics relevant to clinical } \\
\text { dental practice }\end{array}$ & 1.00 & 5.00 & 3.0536 & 0.84034 \\
\hline \multicolumn{5}{|l|}{ Be familiar with } \\
\hline Q25. Pharmacology in general medicine & 1.00 & 5.00 & 2.7321 & 0.84188 \\
\hline Q26. Environmental issues relevant to their use & 1.00 & 5.00 & 3.0893 & 0.81524 \\
\hline
\end{tabular}

Problem-oriented courses with small groups cannot be realized because of the high number of students. Previously we observed that the success rate of students who attended a problem-oriented course was higher than when the same students attended a lecture-based course only..$^{10}$ In this type of learning method, the information given to solve the problem cases is more memorable, and the courses are designed to provide students with clinical competency development to manage the health of patients in terms of dentistry-related illness. Self-directed learning and communication skills contribute to several of the supporting competences adopted by the ADEE. ${ }^{5}$ Appropriate teaching and learning methods are required to gain the defined competencies.
On the contrary, as the number of patients admitted to our school is high (approximately the number of patients seen is 50,000, and number of procedures applied is 150,000 per year) and has much diversity, students were more confident with stating "have competence" than "have knowledge" (three questions were rated somewhat, four questions were rated much).

In a report by the American Dental Education Association (ADEA), ${ }^{9}$ it was emphasized that case-based/ problem-based teaching and learning techniques should be designed to support oral-systemic diagnostic approaches. If basic science education is taught with a case-based problem-solving approach in the clinical years of the dental curriculum, then it has been determined that certain skills can be acquired. 
Table 2: Frequency distribution of Likert-scale values for the 26 questionnaire items

\begin{tabular}{|c|c|c|c|c|c|c|c|c|c|c|}
\hline \multirow{4}{*}{$\begin{array}{l}\text { Have knowledge of } \\
\text { Q1 }\end{array}$} & \multicolumn{2}{|c|}{1} & \multicolumn{2}{|c|}{2} & \multicolumn{2}{|c|}{3} & \multicolumn{2}{|c|}{4} & \multicolumn{2}{|c|}{5} \\
\hline & \multirow[t]{2}{*}{$n$} & \multirow[t]{2}{*}{$\%$} & \multirow[t]{2}{*}{$n$} & \multirow[t]{2}{*}{$\%$} & \multirow[t]{2}{*}{$n$} & \multirow[t]{2}{*}{$\%$} & \multirow[t]{2}{*}{$n$} & \multirow[t]{2}{*}{$\%$} & \multirow[t]{2}{*}{$n$} & \multirow[t]{2}{*}{$\%$} \\
\hline & & & & & & & & & & \\
\hline & & & 6 & 10.7 & 26 & 46.4 & 19 & 33.9 & 5 & 8.9 \\
\hline Q2 & & & 2 & 3.6 & 18 & 32.1 & 26 & 46.4 & 10 & 17.9 \\
\hline Q3 & 2 & 3.6 & 9 & 16.1 & 26 & 46.4 & 13 & 23.2 & 6 & 10.7 \\
\hline Q4 & 1 & 1.8 & 9 & 16.1 & 21 & 37.5 & 20 & 35.7 & 5 & 8.9 \\
\hline Q5 & & & 14 & 25.0 & 20 & 35.7 & 17 & 30.4 & 5 & 8.9 \\
\hline Q6 & 3 & 5.4 & 16 & 28.6 & 22 & 39.3 & 14 & 25.0 & 1 & 1.8 \\
\hline Q7 & 2 & 3.6 & 14 & 25.0 & 35 & 62.5 & 4 & 7.1 & 1 & 1.8 \\
\hline Q8 & 1 & 1.8 & 11 & 19.6 & 22 & 39.3 & 14 & 25.0 & 8 & 14.3 \\
\hline Q9 & 1 & 1.8 & 8 & 14.3 & 31 & 55.4 & 14 & 25.0 & 2 & 3.6 \\
\hline Q10 & 1 & 1.8 & 20 & 35.7 & 30 & 53.6 & - & - & 5 & 8.9 \\
\hline Q11 & & & 1 & 1.8 & 20 & 35.7 & 30 & 53.6 & 5 & 8.9 \\
\hline Q12 & 1 & 1.8 & 14 & 25.0 & 30 & 53.6 & 9 & 16.1 & 2 & 3.6 \\
\hline Q13 & 4 & 7.1 & 11 & 19.6 & 29 & 51.8 & 11 & 19.6 & 1 & 1.8 \\
\hline Q14 & & & 8 & 14.3 & 24 & 42.9 & 21 & 37.5 & 3 & 5.4 \\
\hline Q15 & & & 4 & 7.1 & 26 & 46.4 & 25 & 44.6 & 1 & 1.8 \\
\hline Q16 & & & 8 & 14.3 & 26 & 46.4 & 21 & 37.5 & 1 & 1.8 \\
\hline Q17 & 1 & 1.8 & 10 & 17.9 & 34 & 60.7 & 10 & 17.9 & 1 & 1.8 \\
\hline \multicolumn{11}{|c|}{ Be competent at } \\
\hline Q18 & & & 12 & 21.4 & 18 & 32.1 & 23 & 41.1 & 3 & 5.4 \\
\hline Q19 & & & 6 & 10.7 & 23 & 41.1 & 23 & 41.1 & 4 & 7.1 \\
\hline Q20 & & & 2 & 3.6 & 14 & 25.0 & 26 & 46.4 & 14 & 25.0 \\
\hline Q21 & 1 & 1.8 & 10 & 17.9 & 25 & 44.6 & 14 & 25.0 & 6 & 10.7 \\
\hline Q22 & 4 & 7.1 & 14 & 25.0 & 22 & 39.3 & 9 & 16.1 & 7 & 12.5 \\
\hline Q23 & 1 & 1.8 & 10 & 17.9 & 19 & 33.9 & 22 & 39.3 & 4 & 7.1 \\
\hline Q24 & 2 & 3.6 & 10 & 17.9 & 29 & 51.8 & 13 & 23.2 & 2 & 3.6 \\
\hline \multicolumn{11}{|c|}{ Be familiar with } \\
\hline Q25 & 2 & 3.6 & 21 & 37.5 & 25 & 44.6 & 6 & 10.7 & 2 & 3.6 \\
\hline Q26 & 1 & 1.8 & 11 & 19.6 & 28 & 50.0 & 14 & 25.0 & 2 & 3.6 \\
\hline
\end{tabular}

1 to 5: Answering options for the Likert scale; 1: Not much; 2: Little; 3: Somewhat; 4: Much; 5: A great deal

Table 3: Descriptive statistics and frequency distribution for the six questionnaire items related to qualification of education $(n=56)$

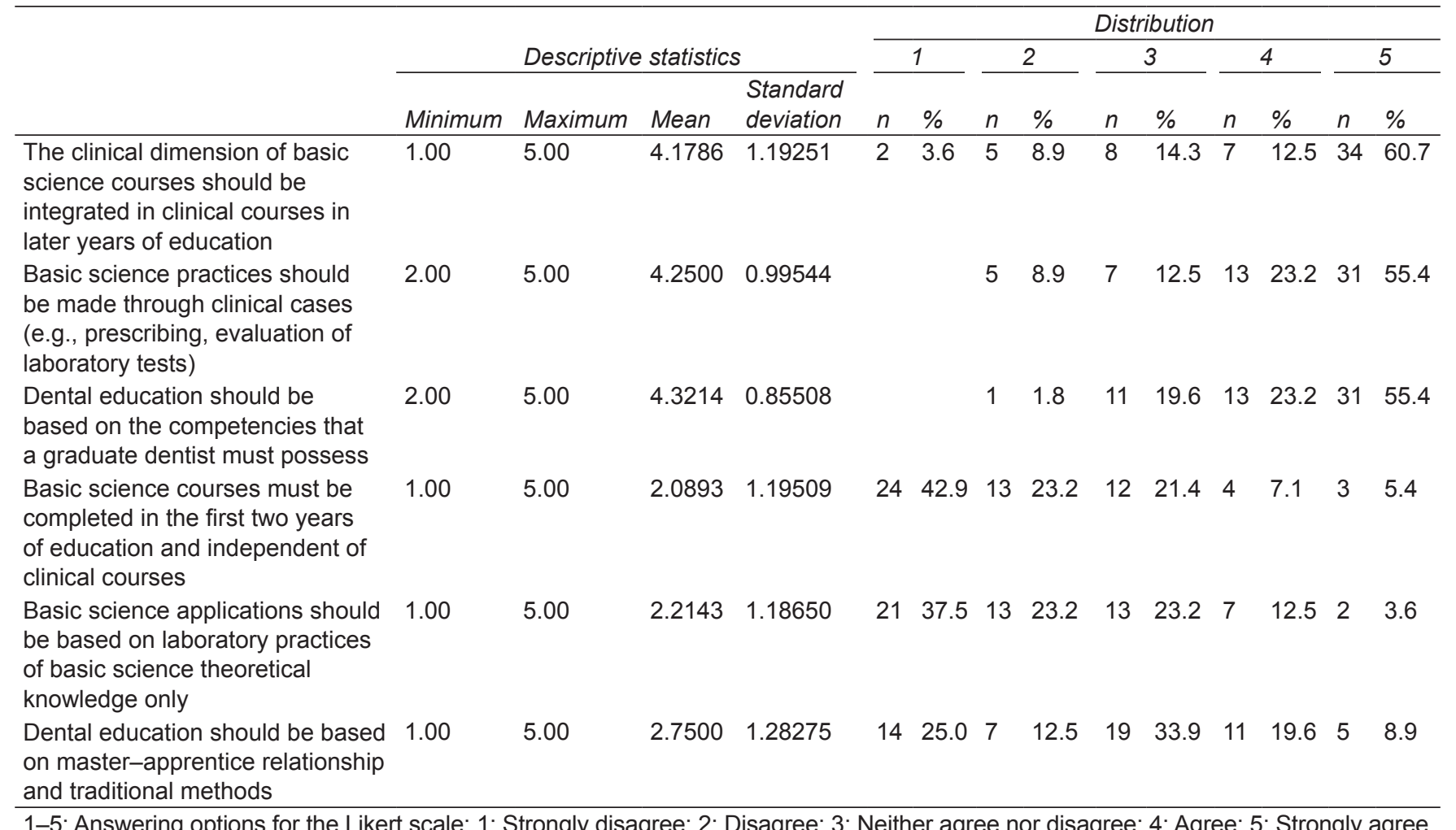
1-5: Answering options for the Likert scale; 1: Strongly disagree; 2: Disagree; 3: Neither agree nor disagree; 4: Agree; 5: Strongly agree 
Teaching of basic science subjects in parallel to clinical education and clinical application will be essential to modeling new patient-centered professional practices. In the study of Henzi et al, ${ }^{3}$ students thought that "basic sciences" should be more integrated with "clinical dentistry" courses and "basic sciences" courses should be designed with a creative and innovative approach, rather than teaching them to pass exams. In our study, most of the students approved of integrated education in the evaluation of qualification of education.

\section{CONCLUSION}

The most important learning objective of dental education must be to gain competencies to make a definite evaluation of oral and dental diseases and help promote early diagnosis of systemic diseases. To reach these goals, undergraduate dental education should ensure that new dental graduates become independent practitioners and continue to develop professional knowledge, understanding, and skills.

In order for the graduate dentists achieve these required qualifications, undergraduate dental education should be modified including reducing the number of students and using student-centered learning models.

\section{ACKNOWLEDGMENTS}

Authors would like to thank all the students who participated in this study and David F. Chapman for his assistance in editing this manuscript.

\section{REFERENCES}

1. Yip HK, Smales RJ. Review of competency-based education in dentistry. Br Dent J 2000 Sep;189(6):324-326.

2. Snyman WD, Kroon J. Vertical and horizontal integration of knowledge and skills-a working model. Eur J Dent Educ 2005 Feb;9(1):26-31.

3. Henzi D, Davis E, Jasinevicius R, Hendricson W. In the students' own words: what are the strengths and weaknesses of the dental school curriculum? J Dent Educ 2007 May;71(5):632-645.

4. Henzi D, Davis E, Jasinevicius R, Hendricson W. North American dental students perspectives about their clinical education. J Dent Educ 2006 Apr;70(4):361-377.

5. Cowpe J, Plasschaert A, Harzer W, Vinkka-Puhakka H, Walmsley AD. Profile and competences for the graduating European dentist-update 2009. Eur J Dent Educ 2010 Nov;14(4):193-202.

6. Cardall WR, Rowan RC, Bay C. Dental education from the students' perspective: curriculum and climate. J Dent Educ 2008 May;72(5):600-609.

7. Alpaslan, GH. Profile and competences for the European dentist. Turkish language version. Europe: ADEE; 2004.

8. Conway MA, Cohen G, Stanhope N. On the very long-term retention of knowledge acquired through formal education: twelve years of cognitive psychology. J Exp Psychol Gen 1991;120(4):395-409.

9. American Dental Education Association. New opportunities for dentistry in diagnosis and primary health care: report of a panel of the Macy study. Report 1. Wahington (DC): American Dental Education Association; 2006. p. 1-5.

10. Guven Y, Bal F, Issever H, Can Trosala S. A proposal for a problem-oriented pharmacobiochemistry course in dental education. Eur J Dent Educ 2014 Apr;18(1):2-6. 